\title{
The complexation of Eu(III) and Cm(III) with polyacrylate as a model compound for complex polycarboxylates studied by laser fluorescence spectroscopy
}

\author{
Daniel R. Fröhlich ${ }^{\mathrm{a}}$, Petra J. Panak $\mathrm{k}^{\mathrm{a}, \mathrm{b}, *}$ \\ ${ }^{a}$ Ruprecht-Karls-Universität Heidelberg, Physikalisch-Chemisches Institut, Im Neuenheimer Feld 253, 69120, Heidelberg, Germany \\ ${ }^{\mathrm{b}}$ Karlsruher Institut für Technologie, Institut für Nukleare Entsorgung, P.O. Box 3640, 76021, Karlsruhe, Germany
}

\section{A B S T R A C T}

The complexation of the trivalent heavy metals Eu(III) and $\mathrm{Cm}$ (III) with polyacrylate as a model ligand is investigated by time-resolved laser fluorescence spectroscopy (TRLFS) and subsequent thermodynamic modelling (charge neutralization model). The aqueous speciation of both metals is investigated as a function of temperature $\left(20-60^{\circ} \mathrm{C}\right)$ and ligand concentration $(0-0.4 \mathrm{~g} / \mathrm{kg})$ in $0.1 \mathrm{~mol} / \mathrm{kg} \mathrm{NaCl}$ solution $\left(\left[\mathrm{H}^{+}\right]_{\text {total }} \approx 10^{-4} \mathrm{~mol} / \mathrm{kg}\right)$. Only one complex species is observed at all experimental conditions. With increasing temperature the aqueous Eu(III) and Cm(III) speciation is slightly shifted towards the complexes species. This effect is attributed to the stronger deprotonation of the polymer, which is also reflected by an increase of its loading capacity. The complex stability constants, however, show no visible temperature dependency. $\log \beta^{\prime}(\mathrm{T})$ ranges between 5.8 and 5.9 for both $\mathrm{Eu}(\mathrm{III})$ and $\mathrm{Cm}(\mathrm{III})$ over the whole range of experimental conditions.

\section{Introduction}

The ongoing search for appropriate storage sites for nuclear waste has led to a large variety of studies covering a wide range of topics within the field of actinide geochemistry. Besides the description of sorption/migration characteristics and dissolution/solubility phe nomena, complexation reactions of actinides with various inorganic and organic ligands in aqueous solution have been in focus.

High level nuclear waste will be contained in steel canisters in many repository scenarios. The subsequent reducing conditions that will be prevailing in the near field of these storage sites lead to the pre dominance of $+3(\mathrm{Pu}, \mathrm{Am}, \mathrm{Cm})$ and $+4(\mathrm{U}, \mathrm{Np})$ as most relevant oxidation states of the included actinides [1]. As a result, the geo chemical properties of trivalent actinides are particularly interesting and have been studied extensively during the past decades.

With respect to complexation reactions, a variety of natural and anthropogenic organic ligands has been investigated regarding their impact on the aqueous speciation of trivalent actinides. The studies range from small organic ligands present in natural clay formations (e.g. formate [2,3], acetate [4 8], etc.) to simple dicarboxylates (e.g. oxalate [9 11], malonate [12,13], etc.) and complex macromolecular natural compounds (e.g. fulvic [14 17] and humic acids [17 26]) and synthetic polycarboxylates relevant for the adjustment of the physical properties of cement and concrete (e.g. superplasticizer [27,28]).

The characterization of complexes with carboxylic macromolecular ligands (especially humic substances) has been an ongoing research interest to the scientific community, leading to the implementation of new models (e.g. charge neutralization [29] or NICA Donnan model [30]) to describe the complex stability with complexing agents of rather undefined structure and molecular size. From spectroscopic studies, it is known that $\mathrm{Cm}$ (III) forms only one complex with humic substances, showing a very well defined emission spectrum. However, there are still open questions, whether coordination with carboxylic functions de termines the interaction process or other functional groups are in volved, too. Only a few studies can be found covering this topic; for example Schmeide et al. studied the effect of blocked phenolic $\mathrm{OH}$ groups of humic substances on the complexation with U(VI) [31]. As a result, no structural differences where observed when comparing U(VI) complexes with blocked or unblocked $\mathrm{OH}$ groups of humic and fulvic acids.

In the present study, we focus on the interaction of $\mathrm{Cm}$ (III), as a representative trivalent actinide, and $\mathrm{Eu}(\mathrm{III})$, as a frequently used crystallochemical analog, with polyacrylate. This compound, which is composed of a simple carboxylic polymer chain, is investigated as a model ligand for more complex polycarboxylates (e.g. humic substances or superplasticizers). Furthermore, the effect of temperature on the complexation reaction is studied in the range of $2060^{\circ} \mathrm{C}$.

\footnotetext{
${ }^{*}$ Corresponding author. Ruprecht-Karls-Universität Heidelberg, Physikalisch-Chemisches Institut, Im Neuenheimer Feld 253, 69120, Heidelberg, Germany.

E-mail address: petra.panak@kit.edu (P.J. Panak).
} 


\section{Experimental section}

\subsection{Sample preparation}

The Eu(III) stock solution was prepared by dissolution of europium oxide (Merck, purity $99+\%$ ) in dilute $\mathrm{HClO}_{4}$ solution. The isotopic composition of the $\mathrm{Cm}$ (III) solution is: $89.7 \% \mathrm{Cm} 248,9.4 \% \mathrm{Cm} 246$,

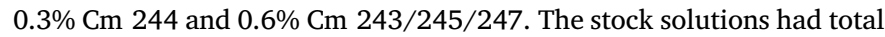
metal concentrations of $1 \times 10^{-4} \mathrm{~mol} / \mathrm{kg}$ for $\mathrm{Eu}(\mathrm{III})$ and $2.5 \times 10^{-7}$ for $\mathrm{Cm}$ (III). The stock solution of sodium polyacrylate (Sigma Aldrich) had a concentration of $5 \mathrm{~g} / \mathrm{kg}$ and was prepared by dissolution of the solid. Its average molar weight equals $\sim 2.100 \mathrm{~g} / \mathrm{mol}$, its proton ex change capacity $0.0106 \mathrm{eq} / \mathrm{g}$.

For all TRLFS measurements, $25 \mu \mathrm{L}$ of the respective stock solution were mixed with $865 \mu \mathrm{L}$ distilled water, $100 \mu \mathrm{L} 1 \mathrm{~mol} / \mathrm{kg} \mathrm{NaCl}$ solution and $10 \mu \mathrm{L} 0.01 \mathrm{~mol} / \mathrm{kg} \mathrm{HCl}$ solution. At these experimental conditions hydrolysis, complexation with chloride and carbonate do not affect Eu (III) or Cm(III) speciation and the impact of poly acrylate on the aqu eous speciation of both trivalent metals with increasing ligand con centration can be tracked ideally. At each investigated temperature (20 $60{ }^{\circ} \mathrm{C}$ ), the sample solution was titrated with aliquots of the poly acrylate stock solution until the measured fluorescence spectrum did not change further, indicating quantitative complexation of the triva lent metal ion.

\subsection{TRLFS}

The TRLFS system is composed of a pulsed Nd:YAG (Surelite II, Continuum, USA) pumped dye laser system (Narrowscan, Radiant Dyes Laser \& Accessories GmbH, Germany) using the dye Exalite 398 and a detector system consisting of a Shamrock SR 303i imaging spectrograph and an iStar II ICCD camera (both Andor Technology PLC, Northern Ireland). The repetition rate was set to $10 \mathrm{~Hz}$, the pulse energy gen erally ranged between 1 and $3 \mathrm{~mJ}$. Curium was excited at $396.6 \mathrm{~nm}$, Europium was excited at $394.0 \mathrm{~nm}$. The sample solutions were filled into quartz cuvettes embedded in a copper block. The temperature of the block was controlled using a water bath thermostat (K6 mpc NR, Peter Huber Kältemaschinen GmbH, Germany). All measurements were performed with an initial delay of $1 \mu$ s to exclude short lived fluores cence using the 900 and 1200 lines gratings of the spectrograph for europium and curium, respectively.

\subsection{Experimental data processing}

Thermodynamic data are derived using the charge neutralization model established by Kim and Czerwinksi [29]. Generally, temperature dependent conditional stability constants at a given ionic strength $\left(\beta^{\prime}(\mathrm{T})\right)$ are calculated according to equation (1):

$\beta^{\prime}(T)=\frac{[M(I I I)-L i g]_{e q}}{[M(I I I)]_{e q} \times[\text { Lig }]_{e q}} ; M=E u, C m ;$ Lig = Polyacrylate

With $[\mathrm{M}(\mathrm{III})]_{\mathrm{eq}},[\mathrm{M}(\mathrm{III}) \mathrm{Lig}]_{\mathrm{eq}}$ and $[\mathrm{Lig}]_{\mathrm{eq}}$ being the molar equili brium concentrations of the M(III) aquo ion, the M(III) Lig complex and the free ligand.

The complexation properties of the macromolecular ligand strongly depend on the chosen experimental conditions (e.g. $\mathrm{pH}$ ) which de termine its extent of deprotonation and thus the number of functional groups available for the metal complexation. This is addressed by in troduction of the loading capacity (LC) which is defined by equation (2):

$L C=\frac{[M(I I I)]_{\max }}{[\mathrm{Lig}]_{\text {total }}}$

There $[\mathrm{M}(\mathrm{III})]_{\max }$ is the maximum amount of trivalent metal that can be bound to the macromolecule and [Lig] $]_{\text {total }}$ is the total ligand concentration given in eq $/ \mathrm{kg}$. [Lig] total is defined by the following equation:

$$
[\text { Lig }]_{\text {total }}=\frac{(\operatorname{Lig}) \times P E C}{Z}
$$

(Lig) equals the ligand concentration in $\mathrm{g} / \mathrm{kg}, \mathrm{PEC}$ is the proton exchange capacity of the ligand and $\mathrm{Z}$ is the ionic charge of the co ordinated metal ion. For a simple polymer like polyacrylate, the PEC can be calculated from its molar mass and equals $0.0106 \mathrm{eq} / \mathrm{g}$.

Within this model, it is assumed that each charge of the metal is neutralized by one opposite charge of the coordinating macromolecule. Therefore, in the case of Eu(III) and $\mathrm{Cm}(\mathrm{III})$, three proton exchange sites equal one charge equivalent.

Combination of equations (2) and (3) leads to:

$L C=\frac{Z \times[M(I I I)]_{\max }}{P E C \times(\operatorname{Lig})}$

The free ligand concentration is calculated using equation (5):

$[\mathrm{Lig}]_{e q}=[\mathrm{Lig}]_{\text {total }} \times L C-[M(I I I)-L i g]_{e q}$

Combination of equations (1), (4) and (5) leads to:

$[M(I I I)]_{e q}=L C \times \frac{[M(I I I)]_{e q} \times[L i g]_{t o t a l}}{[M(I I I)-L i g]_{e q}}-\frac{1}{\beta^{\prime}}$

Equation (6) enables the graphical derivation of the LC by linear regression plotting $[\mathrm{M}(\mathrm{III})]_{\mathrm{eq}}$ vs. $[\mathrm{M}(\mathrm{III})]_{\mathrm{eq}} \times[\mathrm{Lig}]_{\text {total }} \times([\mathrm{M}(\mathrm{III})$ Lig $\left.]_{\mathrm{eq}}\right)^{-1}$. Using the experimentally determined speciation of the metal ion complexes and the derived LC value, conditional stability constants $\left(\log \beta^{\prime}(\mathrm{T})\right)$ can be calculated for all experimental conditions.

\section{Results}

\subsection{Time resolved laser fluorescence spectroscopy}

Fig. 1 shows the emission spectra of Eu(III) and Cm(III) at tem peratures of 20 and $60^{\circ} \mathrm{C}$ as a function of the ligand concentration at a given ionic strength in $0.1 \mathrm{~mol} / \mathrm{kg} \mathrm{NaCl}$ solution $\left(\left[\mathrm{H}^{+}\right]_{\text {total }}=1 \times 10^{-4} \mathrm{~mol} / \mathrm{kg}\right)$. For a better tracking of the evolution of the emission bands, all spectra are normalized to the total peak area. For Eu(III), the relative intensity of the ${ }^{5} \mathrm{D}_{0} \rightarrow{ }^{7} \mathrm{~F}_{2}$ emission band in creases continuously with increasing ligand concentration, whereas the relative intensity of the ${ }^{5} \mathrm{D}_{0} \rightarrow{ }^{7} \mathrm{~F}_{1}$ band decreases due to a continuous shift of the aqueous Eu(III) speciation towards complexed species. For $\mathrm{Cm}$ (III), the emission band shifts from $593.5 \mathrm{~nm}$ to $600.6 \mathrm{~nm}$. Similar wavelengths ranging between 599 and $601 \mathrm{~nm}$ have been reported in the literature for the complexation of $\mathrm{Cm}$ (III) with various humic sub stances $[14,16,21,23]$, which are natural polycarboxylic ligands. The isosbestic points, which are visible in the $\mathrm{Cm}$ (III) system, clearly in dicate that only two species are present: the $\mathrm{Cm}$ (III) aquo ion and a $\mathrm{Cm}$ (III) polyacrylate complex species. For both the Eu(III) and the Cm(III) system, changes in the spectral features at a given ligand concentration are pronounced more strongly at higher temperature.

To confirm that only one complex species is formed for both $\mathrm{Cm}$ (III) and $\mathrm{Eu}(\mathrm{III})$, slope analyses are performed. Plotting $\log \left([\mathrm{M}(\mathrm{III}) \mathrm{Lig}]_{\mathrm{eq}} /\right.$ $\left.[\mathrm{M}(\mathrm{III})]_{\mathrm{eq}}\right)$ vs. $\log \left([\mathrm{Lig}]_{\mathrm{eq}}\right)$ should provide a slope of 1 , if only one complex species with stoichiometry 1:1 is formed. Fig. 2 shows data for Eu(III) together with a line of slope $=1$. The results of individual linear regression are summarized in Table 1 for Eu(III) and Cm(III). De pending on metal ion and temperature, the slopes range between 0.81 and 1.25. Therefore, a stoichiometry of $1: 1$ is confirmed. Note that $1: 1$ refers to the fact that one metal ion is coordinated by one charge equivalent of the ligand. In the case of trivalent metals, each metal ion is coordinated by three carboxylic groups, which do not necessarily belong to a single polymer chain.

The speciation of each individual sample is determined by peak 
$[\mathrm{Eu}(\mathrm{III})]=2.5 \times 10^{-6} \mathrm{~mol} / \mathrm{kg} ; 0.1 \mathrm{~mol} / \mathrm{kg} \mathrm{NaCl} ;\left[\mathrm{H}^{+}\right]=10^{-4} \mathrm{~mol} / \mathrm{kg}$
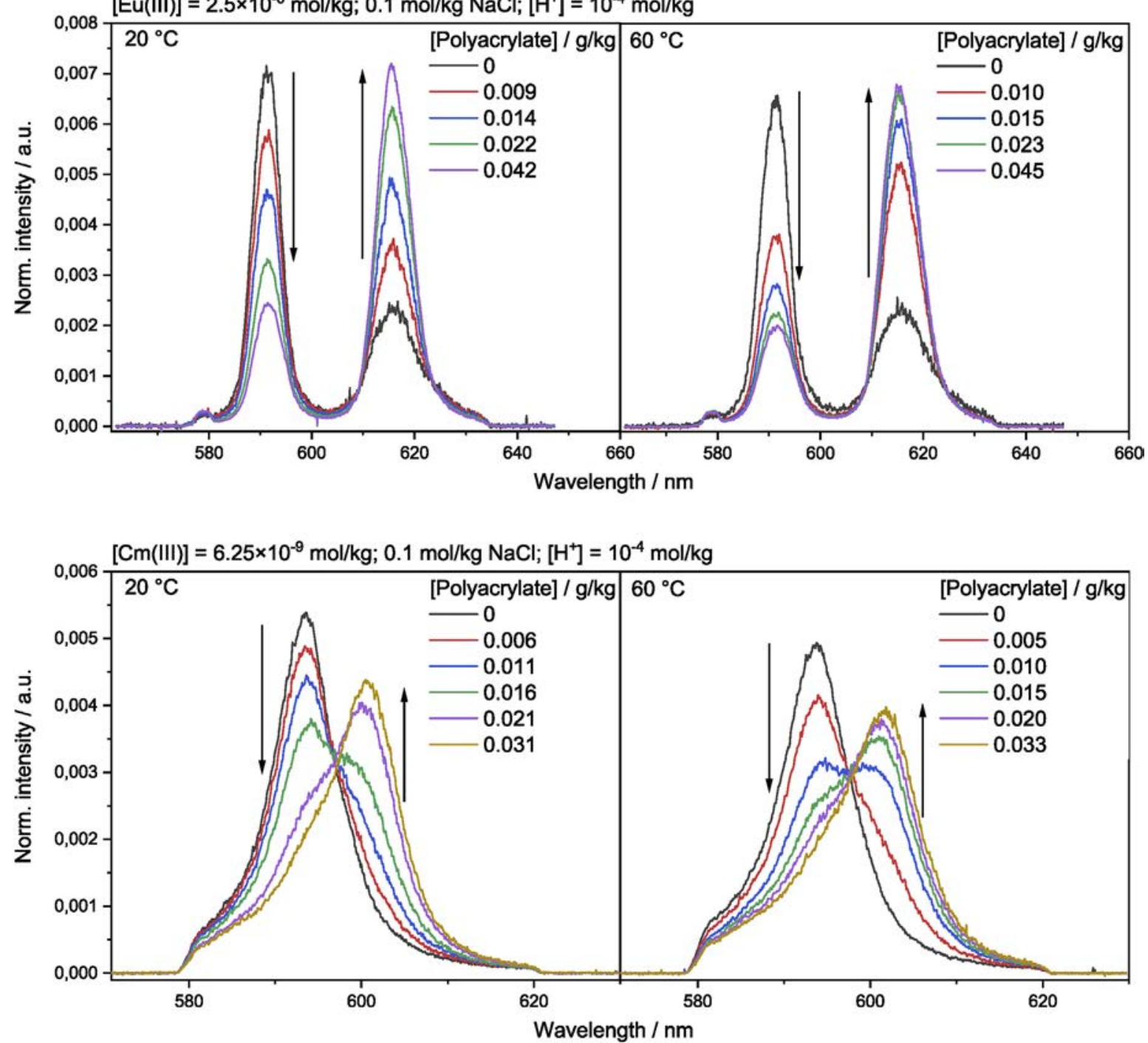

Fig. 1. Emission spectra of $2.5 \times 10^{-6} \mathrm{~mol} / \mathrm{kg} \mathrm{Eu}$ (III) (top) or $6.25 \times 10^{-9} \mathrm{~mol} / \mathrm{kg} \mathrm{Cm}$ (III) (bottom) as a function of the polyacrylate concentration in $0.1 \mathrm{~mol} / \mathrm{kg}$ $\mathrm{NaCl}$ solution $\left(\left[\mathrm{H}^{+}\right]=10^{-4} \mathrm{~mol} / \mathrm{kg}\right)$ at 20 (left) and $60^{\circ} \mathrm{C}$ (right).

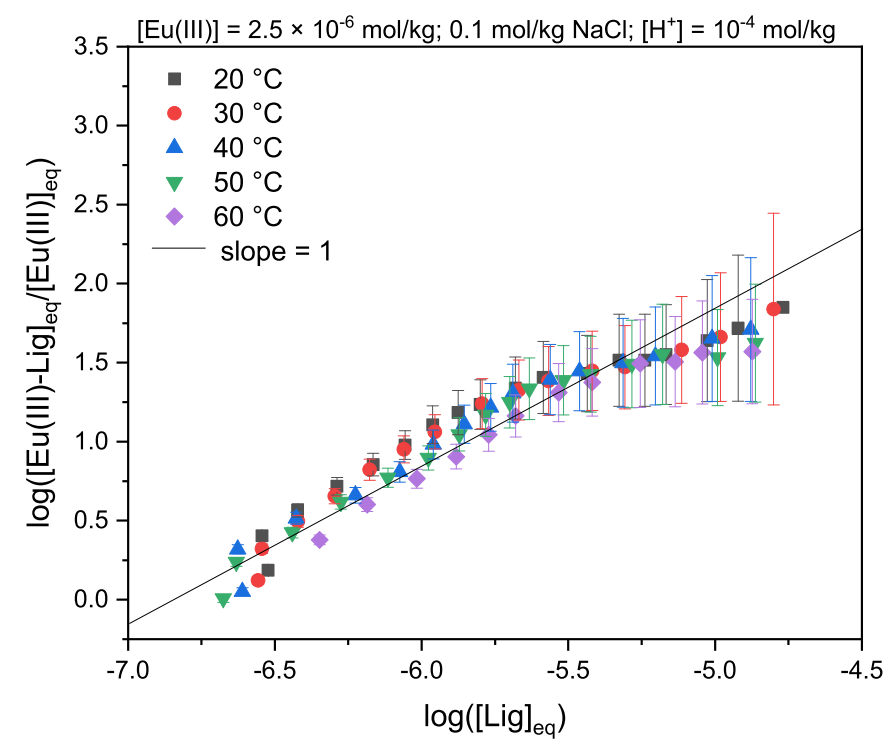

Fig. 2. Slope analyses for the formation of the Eu(III)-polyacrylate complex in $0.1 \mathrm{~mol} / \mathrm{kg} \mathrm{NaCl}$ solution $\left(\left[\mathrm{H}^{+}\right]=10^{-4} \mathrm{~mol} / \mathrm{kg}\right)$ at $20-60{ }^{\circ} \mathrm{C}$.
Table 1

Slope analyses for the formation of the Eu(III)- and Cm(III)-polyacrylate complex at $\mathrm{T}=20-60^{\circ} \mathrm{C}$.

\begin{tabular}{lll}
\hline $\mathrm{T} /{ }^{\circ} \mathrm{C}$ & \multicolumn{2}{l}{ Slope } \\
\cline { 2 - 3 } & $\mathrm{Eu}(\mathrm{III})$ & $\mathrm{Cm}(\mathrm{III})$ \\
\hline 20 & $0.81 \pm 0.11$ & $1.19 \pm 0.20$ \\
30 & $0.94 \pm 0.08$ & $1.25 \pm 0.06$ \\
40 & $0.89 \pm 0.08$ & $1.10 \pm 0.06$ \\
50 & $0.82 \pm 0.10$ & $1.18 \pm 0.08$ \\
60 & $0.87 \pm 0.10$ & $1.16 \pm 0.06$
\end{tabular}

deconvolution using the pure component spectra of the aquo ion and the complex species of Eu(III) or Cm(III).

Lastly, it has to be noted that the Eu(III) complex species exhibits a visibly higher quantum yield compared to the Eu(III) aquo ion, which is considered by the introduction of the fluorescence intensity factor $\left(f_{i}\right.$ factor). This has to be taken into account for the calculation of $\log \beta^{\prime}(\mathrm{T})$ as the molar fractions $\left(\chi_{i}\right)$ of the different species equal the relative intensity $I_{i, r e l}$ devided by the respective $f_{i}$ fector:

$\chi_{i}=I_{i, r e l} / f_{i}$ 
Table 2

Fluorescence intensity factors ( $f_{i}$-factors) of the Eu(III)- and $\mathrm{Cm}$ (III)-polyacrylate complex species at $\mathrm{T}=20-60{ }^{\circ} \mathrm{C}$.

\begin{tabular}{lll}
\hline $\mathrm{T} /{ }^{\circ} \mathrm{C}$ & \multicolumn{2}{l}{ fi-factor } \\
\cline { 2 - 3 } & $\mathrm{Eu}(\mathrm{III})$ & $\mathrm{Cm}(\mathrm{III})$ \\
\hline 20 & 8.3 & 1.4 \\
30 & 8.2 & 1.7 \\
40 & 9.5 & 1.5 \\
50 & 6.9 & 1.7 \\
60 & 9.9 & 1.1 \\
Average & $8.6 \pm 1.2$ & $1.5 \pm 0.2$ \\
\hline
\end{tabular}

The $f_{i}$ factor of the complex species does not show a continuous change with increasing temperature. Therefore, an average value of $8.6 \pm 1.2$ (with the $f_{i}$ factor of the Eu(III) aquo ion equaling 1 ) is used for the data evaluation. For $\mathrm{Cm}(\mathrm{III})$ the $f_{i}$ factor of the $\mathrm{Cm}$ polyacrylate complex is not significantly higher compared to the aquo ion, the average value equals $1.5 \pm 0.2$. The individual $f_{i}$ factors determined at each temperature are summarized in Table 2.

The experimentally determined $\mathrm{Eu}(\mathrm{III})$ speciation ([Eu(III) $]_{\mathrm{eq}}$ and $[\mathrm{Eu}(\mathrm{III}) \mathrm{Lig}]_{\mathrm{eq}}$ ) and the calculated free polyacrylate concentration in equilibrium ([Lig $]_{\text {eq }}$ ) are used to determine the LC of the polymer at the chosen experimental conditions. The resulting values at each tem perature are presented in Table 3.

The accurate determination of the LC requires a systematic change of the free ligand concentration throughout the experimental series. At very low metal concentration, as applied for $\mathbf{C m}$ (III) within this work, a proper determination of LC is not possible, as the ligand concentration is almost unaffected by the complexation reaction. Therefore, $L C$ values for $\mathrm{Eu}(\mathrm{III})$ are used for the determination of the thermodynamic data for Cm(III), as the LC is supposed to be identical due to the constant ex perimental conditions and very similar chemical properties of $\operatorname{Ln}$ (III) and An(III) . This is a standard procedure, which has also been applied in earlier studies, when determining Am(III) and $\mathrm{Cm}$ (III) data for the complexation with fulvic acid [15].

It is visible, that the LC increases slightly with increasing tempera ture. This leads to a stronger deprotonation of the carboxylic functions of the macromolecule, which is in line with the more pronounced complexation observed at higher temperature.

The aqueous speciation of $\mathrm{Eu}(\mathrm{III})$ and $\mathrm{Cm}$ (III) and the $\mathrm{LC}$ values given in Table 3 are used to calculate the conditional stability constants of the formed polyacrylate complexes $\left(\beta^{\prime}(\mathrm{T})\right)$, taking into account the $f_{i}$ factors of the respective species (Table 2). Table 4 summarizes the average stability constants for $\mathrm{Eu}(\mathrm{III})$ and $\mathrm{Cm}$ (III) at each temperature. The $\log \beta^{\prime}(\mathrm{T})$ values range between 5.8 and 5.9. They are completely unaffected by the increase of temperature and show a remarkable agreement for both investigated trivalent metal ions. Furthermore, it can be concluded, that the effect of temperature, which is visible in Fig. 1, is not attributed to a change of the complex stability but to the change in the LC.

The present results are compared to literature data on the com plexation of $\mathrm{Cm}$ (III) with various polycarboxylic ligands. Room

Table 3

Loading capacity of polyacrylate in $0.1 \mathrm{~mol} / \mathrm{kg}$ $\mathrm{NaCl}$ solution $\left(\left[\mathrm{H}^{+}\right]_{\text {total }}=10^{-4} \mathrm{~mol} / \mathrm{kg}\right)$ as a function of the temperature.

\begin{tabular}{ll}
\hline $\mathrm{T} /{ }^{\circ} \mathrm{C}$ & $\mathrm{LC}$ \\
\hline 20 & $0.030 \pm 0.002$ \\
30 & $0.032 \pm 0.003$ \\
40 & $0.041 \pm 0.001$ \\
50 & $0.041 \pm 0.002$ \\
60 & $0.050 \pm 0.005$ \\
\hline
\end{tabular}

Table 4

Conditional stability constants for the formation of the Eu(III)- and Cm(III)polyacrylate complex in $0.1 \mathrm{~mol} / \mathrm{kg} \mathrm{NaCl}$ solution $\left(\left[\mathrm{H}^{+}\right]_{\text {total }}=10^{-4} \mathrm{~mol} / \mathrm{kg}\right)$ as a function of the temperature.

\begin{tabular}{lll}
\hline $\mathrm{T} /{ }^{\circ} \mathrm{C}$ & $\log \beta^{\prime}(\mathrm{T})$ & \\
\cline { 2 - 3 } & $\mathrm{Eu}(\mathrm{III})$ & $\mathrm{Cm}(\mathrm{III})$ \\
\hline 20 & $5.87 \pm 0.28$ & $5.78 \pm 0.42$ \\
30 & $5.88 \pm 0.22$ & $5.83 \pm 0.45$ \\
40 & $5.83 \pm 0.25$ & $5.92 \pm 0.22$ \\
50 & $5.82 \pm 0.20$ & $5.86 \pm 0.34$ \\
60 & $5.76 \pm 0.15$ & $5.84 \pm 0.25$ \\
\hline
\end{tabular}

temperature data for $\mathbf{C m}$ (III) complexes with different humic [21,23] and fulvic acids [14 16] at comparable ionic strength provided log $\beta^{\prime}$ values ranging between 5.6 and 6.6. The only temperature dependent study showed an increase of $\log \beta^{\prime}(\mathrm{T})$ with increasing temperature by 0.40 .6 in the temperature range of $2080^{\circ} \mathrm{C}$ depending on the used fulvic acid.

Another study investigated the complexation of Eu(III) with a polycarboxylate superplasticizer synthesized from acrylic acid [28]. Here, $\log \beta^{\prime}(\mathrm{T})$ decreased slightly from 6.5 at $20^{\circ} \mathrm{C}$ to 5.9 at $80^{\circ} \mathrm{C}$. In this case, the differing temperature dependence is due to structural differences resulting from the (poly)ethylene glycol chains which se parate the coordinating functional groups and make the whole macro molecule sterically more demanding.

Taking into account the range of literature data for the complexa tion of trivalent metals with different synthetic or natural poly carboxylates (e.g. humic substances, cement admixtures, etc.), the va lues determined in the present study belong to the lower values of the spectrum while still lying in the same range. If the temperature de pendency of the stability constants is connected to structural properties of the macromolecule, the lack of temperature effect in the case of polyacrylate might also be attributed to its structural characteristics, e.g. the missing of side chains and additional functional groups. However, a more detailed and systematic investigation of structural variations within these kind of polymers might be necessary to clarify this complexation behavior.

\section{Conclusion}

The present study provides detailed thermodynamic information on the complexation reaction of the trivalent actinide $\mathbf{C m}$ (III), and Eu(III) as a frequently used crystallochemical analog with polyacrylate using time resolved laser fluorescence spectroscopy.

The conditional stability constants $\left(\log \beta^{\prime}(\mathrm{T})\right.$ ) in $0.1 \mathrm{~mol} / \mathrm{kg} \mathrm{NaCl}$ solution were found to be independent of the applied temperature in the range of $2060{ }^{\circ} \mathrm{C}$ for both metals, ranging between 5.8 5.9. As a result, the endothermic effect on the complexation reaction, which is observed in the emission spectra, results from the deprotonation of the coordinating ligand. This is reflected by the increase in loading capacity with increasing temperature. The results of slope analyses point out, that one metal ion is coordinated by three carboxylic groups of the polymer, thus verifying the validity of the applied charge neutralization model.

Whereas the presently determined thermodynamic constants are located at the lower end of the reported data for various polycarboxylic ligands (including humic substances and cement admixtures), they still lie within the range expected for macromolecular carboxylic ligands that do not form chelate complexes.

Previous complexation studies of trivalent actinides and lanthanides showed, that polycarboxylates provide a rather small temperature de pendency $[7,27,28]$. In the case of polyacrylate, this effect of tem perature is even less pronounced. If changes of the stability constant with increasing temperature are connected to structural characteristics 
of the polycarboxylates, the lack of temperature dependency in the case of polyacrylate might be a result of its simple structure without side chains and additional functional groups.

Regarding the complexation properties, polycarboxylates like polyacrylate are suitable as model ligands. However, more systematic investigations of specific structural features seem to be necessary to further unravel temperature dependent effects.

\section{Acknowledgements}

This work has been supported by the German Federal Ministry of Economics and Energy (BMWi) under contract number 02E11415H.

\section{References}

[1] M.H. Bradbury, B. Baeyens, Far Field Sorption Data Bases for Performance Assessment of a High-Level Radioactive Waste Repository in an Undisturbed Opalinus Clay Host Rock. PSI Technical Report 03-08, Paul Scherrer Institut, Villigen, Switzerland, 2003

[2] D.R. Fröhlich, A. Skerencak-Frech, P. Panak, J. Appl. Geochem. 61 (2015) 312-317.

[3] D.R. Fröhlich, A. Kremleva, A. Rossberg, A. Skerencak-Frech, C. Koke, S. Krüger, N. Rösch, P. Panak, J. Inorg. Chem. 56 (2017) 6820-6829.

[4] G.R. Choppin, J.K. Schneider, J. Inorg. Nucl. Chem. 32 (1970) 3283-3288.

[5] G.R. Choppin, Q. Liu, J.C. Sullivan, Inorg. Chem. 24 (1985) 3968-3969.

[6] V.K. Rao, G.R. Mahajan, P.R. Natarajan, Inorg. Chim. Acta 128 (1987) 131-134.

[7] D.R. Fröhlich, A. Skerencak-Frech, P. Panak, J. Dalton Trans. 43 (2014) 3958-3965.

[8] D.R. Fröhlich, A. Skerencak-Frech, N. Bauer, A. Rossberg, P.J. Panak, J. Synchrotron Radiat. 22 (2015) 99-104.

[9] G.R. Choppin, J.F. Chen, Radiochim. Acta 74 (1996) 105-110.

[10] A. Skerencak-Frech, M. Maiwald, M. Trumm, D.R. Fröhlich, P. Panak, J. Inorg. Chem. 54 (2015) 1860-1868.

[11] M. Borkowski, R. Moore, M. Bronikowski, J.P. Chen, O. Pokrovsky, Y. Xia,
G. Choppin, J. Radioanal. Nucl. Chem. 248 (2001) 467-471.

[12] P. Thakur, P.N. Pathak, T. Gedris, G.R. Choppin, J. Solut. Chem. 38 (2009) 265-287.

[13] A. Skerencak-Frech, M. Trumm, D.R. Fröhlich, P. Panak, J. Inorg. Chem. 56 (2017) $10172-10180$

[14] D.R. Fröhlich, A. Skerencak-Frech, M. Gast, P. Panak, J. Dalton Trans. 43 (2014) 15593-15601.

[15] G. Buckau, J.I. Kim, R. Klenze, D.S. Rhee, H. Wimmer, Radiochim. Acta 57 (1992) 105-111.

[16] F. Claret, T. Schäfer, T. Rabung, M. Wolf, A. Bauer, G. Buckau, Appl. Geochem. 20 (2005) 1158-1168.

[17] N.A. Wall, M. Borkowski, J. Chen, G.R. Choppin, Radiochim. Acta 90 (2002) 563-568.

[18] J.I. Kim, D.S. Rhee, H. Wimmer, G. Buckau, R. Klenze, Radiochim. Acta 62 (1993) $35-43$

[19] K.R. Czerwinski, J.I. Kim, D.S. Rhee, G. Buckau, Radiochim. Acta 72 (1996) 179-187.

[20] K. Schmeide, T. Reich, S. Sachs, G. Bernhard, Inorg. Chim. Acta 359 (2006) $237-242$

[21] J.I. Kim, H. Wimmer, R. Klenze, Radiochim. Acta 54 (1991) 35-41.

[22] P.J. Panak, R. Klenze, J.I. Kim, Radiochim. Acta 74 (1996) 141-146.

[23] H.S. Shin, B.H. Lee, J.G. Choi, H. Moon, Radiochim. Acta 69 (1995) 185-189.

[24] R.A. Torres, G.R. Choppin, Radiochim. Acta 35 (1984) 143-148.

[25] J.I. Kim, G. Buckau, E. Bryant, R. Klenze, Radiochim. Acta 48 (1989) 135-143.

[26] J.I. Kim, D.S. Rhee, G. Buckau, A. Morgenstern, Radiochim. Acta 79 (1997) 173-181.

[27] D.R. Fröhlich, M.M. Maiwald, F. Taube, J. Plank, P. Panak, J. Dalton Trans. 46 (2017) 4093-4100.

[28] D.R. Fröhlich, C. Koke, M.M. Maiwald, C. Chomyn, J. Plank, P. Panak, J. Spectrochim. Acta A 207 (2019) 270-275.

[29] J.I. Kim, K.R. Czerwinski, Radiochim. Acta 73 (1996) 5-10.

[30] D.G. Kinniburgh, C.J. Milne, M.F. Benedetti, J.P. Pinheiro, J. Filius, L.K. Koopal, W.H. Van Riemsdijk, Environ. Sci. Technol. 30 (1996) 1687-1698.

[31] K. Schmeide, S. Sachs, M. Bubner, T. Reich, K.H. Heise, G. Bernhard, Inorg. Chim. Acta 351 (2003) 133-140. 
Karlsruher Institut für Technologie

\section{Repository KITopen}

Dies ist ein Postprint/begutachtetes Manuskript.

Empfohlene Zitierung:

Fröhlich, D. R.; Panak, P. J.

The complexation of $\mathrm{Eu}(\mathrm{III})$ and $\mathrm{Cm}(\mathrm{III})$ with polyacrylate as a model compound for complex polycarboxylates studied by laser fluorescence spectroscopy. 2019. Journal of luminescence, 212. doi: $10.5445 / I R / 1000099460$

Zitierung der Originalveröffentlichung:

Fröhlich, D. R.; Panak, P. J.

The complexation of Eu(III) and $\mathrm{Cm}(\mathrm{III})$ with polyacrylate as a model compound for complex polycarboxylates studied by laser fluorescence spectroscopy. 2019. Journal of luminescence, $212,166-170$.

doi:10.1016/i.jlumin.2019.04.037 